\title{
The Use of Iliac Side Branch Devices in Patients with Aortoiliac Aneurysm
}

\section{Verwendung iliakaler Bifurkationsprothesen bei Patienten mit aorto-iliakalem Aneurysma}

Authors

Affiliations
V. Maus ${ }^{1}$, P. Kurz' , C. M. Sommer¹, A. Massmann³ , A. Hatopp', S. Erpenbach¹, K. Thomas', T. Saalmüller², H. Meißner², T. Hupp ${ }^{2}$, G. M. Richter ${ }^{1}$

Clinic of Diagnostic and Interventional Radiology, Katharinenhospital Stuttgart, Germany

2 Clinic of Vascular Surgery, Katharinenhospital Stuttgart, Germany

3 Clinic of Diagnostic and Interventional Radiology, Saarland University Medical Center, Homburg, Germany

\section{Key Words}

- endovascular aortic repair

- aortic aneurysm

- iliac artery aneurysm

- iliac side branch device

- endoleak received $\quad 30.9 .2015$

accepted $\quad 31.3 .2016$

Bibliography

DOI http://dx.doi.org/

10.1055/s-0042-105764

Published online: 7.7.2016

Fortschr Röntgenstr 2016; 188:

746-752 @ Georg Thieme

Verlag KG Stuttgart - New York .

ISSN 1438-9029

\section{Correspondence}

Dr. Volker Maus

Institute of Radiology,

Katharinenhospital Stuttgart

Kriegsbergstraße 60

70174 Stuttgart

Germany

Tel.: ++ 49/015256822638

Fax: ++ 49/07 11/27834409

volker-maus@gmx.de

\section{Zusammenfassung}

$\nabla$

Ziel: Ziel der Studie ist die Evaluation der technischen Durchführbarkeit und der Kurzzeitergebnisse endovaskulär mittels iliakaler Bifurkationsprothesen versorgter Patienten mit aorto-iliakalem Aneurysma.

Material und Methoden: Zwischen Oktober 2013 und Juni 2015 wurden insgesamt 17 Patienten (17 männlich; Durchschnittsalter 72,5 Jahre) mit einem behandlungsbedürftigen aorto-iliakalem Aneurysma endosvaskluär mittels einer iliakalen Bifurkationsprothese versorgt und retrospektiv ausgewertet. Primärer Endpunkt war der primäre technische Erfolg, definiert als adäquate Implantation der iliakalen Bifurkationsprothese mit Durchgängigkeit des internen Prothesenschenkels ohne Notwendigkeit einer Re-Intervention innerhalb 30 Tage. Der mittlere Nachsorgezeitraum betrug $8,2 \pm 5,4$ Monate.

Ergebnisse: Insgesamt wurden 18 iliakale Bifurkationsprothesen implantiert mit einer Offenheitsrate von $100 \%$ und einer primären technischen Erfolgsrate von $94,4 \%(n=17)$. Die perioperative Mortalität lag bei $0 \%$. Der durchschnittliche Durchmesser der Aneurysmata von Aorta und Arteria iliaca communis betrug $41 \pm 14$ bzw. $30 \pm 8 \mathrm{~mm}$. In einem Fall kam es peri-interventionell zu einer partiellen Dislokation der Bifurkationsprothese aufgrund erheblich elongierter Iliakalgefäße, wodurch ein iliakales Endoleak Ib entstand, das in einer zweiten Intervention behoben wurde. Bei drei Patienten wurde ein Endoleak Typ II über die Arteria mesenterica inferior festgestellt, die konservativ behandelt wurden. Nach drei Monaten kam es bei einem Patienten zu einem subtotalen thrombotischen Verschluss des Brücken-Stents, der durch intraarterielle Lyse und eine zusätzliche Stentimplantation erfolgreich behoben wurde. Schlussfolgerung: Zusammenfassend ist die endovaskuläre Versorgung aorto-iliakaler Aneurys-

\section{Abstract \\ $\nabla$}

Purpose: The aim of this study was to evaluate the technical feasibility and short-time patency rate of iliac side branch devices based on the authors' institution's experience.

Materials and Methods: Data of 17 patients (all men) with an aortoiliac aneurysm (median age 72.5 years) who underwent endovascular repair between October 2013 and June 2015 (20 months) at our institution was analyzed retrospectively. Primary endpoint was primary technical success, defined as adequate implantation of the iliac branch device with patency of the hypogastric side branch without the need of further re-interventions within 30 days. Mean follow-up was $8.2 \pm 5.4$ months.

Results: Eighteen iliac side branch devices were implanted with a branch patency of $100 \%$ and a primary technical success rate of $94.4 \%(n=17)$. Perioperative 30 days mortality was $0 \%$. The mean diameter of treated abdominal aorta and common iliac artery was $41 \pm 14$ and $30 \pm 8 \mathrm{~mm}$. In one case partial dislocation of the iliac side branch device occurred due to severe kinking of iliac arteries with development of an iliac endoleak type Ib that had to be treated in a second intervention. Three patients $(15 \%)$ showed an endoleak type II from the inferior mesenteric artery without the need of re-intervention. After three months one patient suffered from subtotal thrombotic occlusion of the bridging stent that was successfully resolved through intra-arterial fibrinolytic therapy and additional stent graft implantation.

Conclusion: Summarized, implantation of iliac side branch devices is a feasible technique with favourable short-term results in patients with aortoiliac aneurysm.

Key Points:

- Implantation of iliac side branch devices is a feasible technique. 
mata mittels iliakaler Bifurkationsprothesen eine sichere und erfolgreiche Therapie.

Kernaussagen:

- Implantation von iliakalen Bifurkationsprothesen ist technisch durchführbar.

- Vielversprechende Kurzzeitergebnisse nach Implantation von iliakalen Bifurkationsprothesen bei Patienten mit aorto-iliakalem Aneurysma.

- Sorgfältige Patientenauswahl wichtig, um Komplikationen und Re-Interventionen zu vermeiden.
Distinguish short-term results of side branch endografting in patients with aortoiliac aneurysm.

Carefully patient selection is necessary to avoid complications and re-interventions.

Citation Format:

- Maus V, Kurz P, Sommer CM et al. The Use of Iliac Side Branch Devices in Patients with Aortoiliac Aneurysm.. Fortschr Röntgenstr 2016; 188: 746-752

\section{Introduction}

\section{$\nabla$}

Endovascular aortic repair (EVAR) of abdominal aortic aneurysms (AAA) is a safe and feasible treatment option [1-4]. However, $20-40 \%$ of AAAs are associated with aneurysms of iliac arteries, which is unfavorable for standard EVAR. The incidence of isolated iliac artery aneurysms is about $0.008-0.03 \%[5,6]$. Aneurysms of the common iliac artery (CIA) represent an issue for standard EVAR, due to the insufficient distal sealing zone for standard abdominal stent grafts. Moreover, short distal neck or aneurysmal incorporation of the external iliac artery (EIA) necessitates a more sophisticated endovascular technique. The use of a standard stent graft with extension of the distal sealing zone into the EIA and occlusion of the hypogastric artery is described as a technical option [7]. However, unilateral sacrifice of blood flow to the hypogastric artery may cause symptomatic buttock claudication or sexual dysfunction that is self-limiting in the case of good pelvic collateralization, but up to $15 \%$ of the patients remain symptomatic [8]. Rarely, more severe complications such as spinal and colonic ischemia may occur as well [9]. Hence, the first attempts of preserving hypogastric blood flow included surgical re-implantation and bypass of the hypogastric artery in a hybrid approach [10,11]. Endovascular approaches are proposed including the bell-bottom technique, which consists of flared stent grafts with appropriate sizing adapted to the large iliac artery diameters [12]. As an alternative, iliac side branch devices (ISBD) were created to simultaneously eliminate CIA aneurysms with an adequate distal fixation in the EIA while preserving antegrade flow to the hypogastric artery. With this approach sigmoidal malperfusion and endoleak type Ib is prevented [13]. Implantation of ISBD can be performed alone for isolated CIA aneurysms or in combination with standard abdominal stent grafts for combined aorto-iliac aneurysms with excellent short- and mid-term results [14-18].

The aim of this study was to evaluate the technical feasibility and short-time patency rate of the iliac side branch device based on the authors' institution's experience.

\section{Materials and Methods}

\section{$\nabla$}

Between October 2013 and June 201517 male patients (median age 72.5 years, range 64 to 85 ) with AAA and iliac artery aneurysms consecutively underwent endovascular repair using the Cook Zenith iliac side branch device (Cook Medical, Bloomington, IN, USA) at our institution, an tertiary medical center specialized in endovascular intervention. For device planning pre-interventional contrast enhanced computed tomography angiography (CTA) scans were performed with a reconstruction interval of 1 millimeter. Selection criteria included (i) suitable vascular morphology for endovascular repair including a diameter of the CIA of at least $18 \mathrm{~mm}$ for adequate side branch deployment, a nonaneurysmal EIA fixation segment distal to the aneurysm with a length of at least $20 \mathrm{~mm}$ and a diameter (outer wall to outer wall) between 8 and $11 \mathrm{~mm}$ and a non-aneurysmal hypogastric artery segment distal to the aneurysm with a length of at least $10 \mathrm{~mm}$ with a diameter acceptable for proper sealing as well as (ii) non-suitable conditions for surgery including coronary artery disease, major rhythm disorders, chronic obstructive pulmonary disease, renal insufficiency, diabetes mellitus or hostile abdomen. All patients treated with iliac side branch devices were compliant with the instructions for use (IFU). In patients with a short proximal neck ( $<10 \mathrm{~mm}$ ), younger age ( $<65$ years), preexisting occlusion of contralateral hypogastric artery or inferior mesenteric artery (IMA) combination with standard bifurcated abdominal stent grafts were performed. Patient demographics are presented in 0 Table 1.

Indications were fusiform CIA aneurysms $>30 \mathrm{~mm}$ or $>25 \mathrm{~mm}$ with saccular morphology or hypogastric artery aneurysm $>18 \mathrm{~mm}$ with concomitant AAA $(\mathrm{n}=13)$, predominantly CIA aneurysms with an insufficient proximal fixation zone $(n=3$; in one case with bilateral CIA and unilateral hypogastric artery aneurysm) and solitary CIA aneurysm $(n=1)$. Two patients had history of previous abdominal aortic interventions: one patient with solitary CIA aneurysm exhibited open repair with implantation of an aortic tube prosthesis for exclusion of infrarenal AAA years ago, the other patient required proximal repair of a suture-line aneurysm after aortoiliac bypass. Further aneurysm characteristics are shown in 0 Table 2. A total of 18 ISBD were implanted.

Table 1 Patient demographics.

Tab. 1 Patientenmerkmale.

\begin{tabular}{|c|c|c|c|}
\hline patient demographics & value & $\begin{array}{l}\text { standard } \\
\text { deviation }\end{array}$ & percentage \\
\hline number of patients & 17 & & \\
\hline male & 17 & & 100 \\
\hline age & 72.5 & & \\
\hline coronary artery disease & 10 & & 52.6 \\
\hline cardiac arrhythmia & 8 & & 47.0 \\
\hline arterial hypertension & 16 & & 84.2 \\
\hline cerebral ischemia & 1 & & 5.3 \\
\hline pulmonary disease & 4 & & 21.1 \\
\hline renal disease & 7 & & 36.8 \\
\hline diabetes mellitus & 6 & & 31.6 \\
\hline creatinine level [mg/dl] & 1.0 & 0.25 & \\
\hline eGFR $[\mathrm{ml} / \mathrm{min}]$ & 78.7 & 19.5 & \\
\hline dyslipidemia & 6 & & 31.6 \\
\hline body mass index & 27.3 & 4.2 & \\
\hline
\end{tabular}


Table 2 Details of aneurysm morphology.

Tab. 2 Aneurysmamorphologie.

\begin{tabular}{|l|l|}
\hline & $\begin{array}{l}\text { mean } \pm \text { standard } \\
\text { deviation }\end{array}$ \\
\hline $\begin{array}{l}\text { maximum diameter of treated } \\
\text { abdominal aorta [mm] }\end{array}$ & $41 \pm 14$ \\
\hline $\begin{array}{l}\text { maximum diameter of } \\
\text { ipsilateral CIA [mm] }\end{array}$ & $30 \pm 8$ \\
\hline $\begin{array}{l}\text { maximum diameter of } \\
\text { contralateral CIA [mm] }\end{array}$ & $18 \pm 4$ \\
\hline $\begin{array}{l}\text { maximum diameter of } \\
\text { treated hypogastric artery [mm] }\end{array}$ & $19 \pm 1$ \\
\hline
\end{tabular}

The data was analyzed retrospectively on an intention to treat basis with inclusion of consecutive patients. Written informed consent was obtained from all included patients. All indications were made on an interdisciplinary decision including vascular surgeons, interventional radiologists and internal specialists. Primary endpoint was primary technical success, defined as adequate implantation of the ISBD with patency of the hypogastric side branch without the need of further re-interventions within 30 days. Secondary endpoint was assisted technical success, defined as patency of the ISBD after repeated interventional revision within the perioperative period (30 days). In all patients CT scans were performed within the perioperative period. All patients were affiliated in our follow-up protocol that consisted of a CT scan and review at 6 monthly intervals in the first year and contrast enhanced ultrasound annually thereafter. All values are presented as means \pm standard deviation and ranges or as frequency and percentages.

\section{Iliac Side Branch Deployment}

Procedures were performed in general anesthesia. Endovascular access was achieved through surgical preparation of both common femoral arteries. Fluoroscopic guidance was used for visualization of the ISBD. A super-stiff guidewire (Lunderquist, Cook Medical) was used for advancement and positioning of the ISBD with the distal end of the side branch $10 \mathrm{~mm}$ proximal to the origin of the hypogastric artery. The tip of the pre-loaded catheter within the side branch device was released at the aortic bifurcation by withdrawal of the delivery sheath. A 0.035 inch soft Terumo guide wire (Terumo Medical Corporation, Somerset, NY, USA) was snared (Bard Peripheral Vascular Inc., Tempe, AZ, USA) from the contralateral access. A 12-French (F) up-and-over sheath (W.L. Gore \& Associates, Flagstaff, AZ, USA) was advanced over the 'through-and-through' guide wire to the proximal end of the side branch. Afterwards, the sheath was withdrawn for deployment of the iliac side branch. The hypogastric artery was cannulated through the cross-over sheath using a curved catheter (Berenstein, Cordis, Miami, FL, USA) and a soft Terumo guide wire. A 0.035 inch Rosen wire (Cook Medical) was exchanged for extension of the iliac side branch by a balloon-expandable covered stent graft (Advanta V12, Atrium Medical Corperation, Hudson, $\mathrm{NH}, \mathrm{USA}$ ). The Advanta stent graft was used in our study due to well-established handling experience at our department. Finally, complete deployment of the ISBD and withdrawal of the crossover sheath was performed. Details of implanted materials are shown in $\bullet$ Table 3. Completion angiography was used for confirmation of successful deployment, including patency and sealing. In one patient with a bilateral iliac aneurysm treatment of the
Table 3 Overview of implanted material.

Tab. 3 Implantiertes Material.

\begin{tabular}{|c|c|}
\hline & $\mathbf{n}$ \\
\hline iliac branch graft & 18 \\
\hline ZBIS $10-45-58$ & 1 \\
\hline ZBIS $10-61-41$ & 2 \\
\hline ZBIS $12-45-41$ & 4 \\
\hline ZBIS 12 -45-58 & 8 \\
\hline ZBIS $12-61-41$ & 1 \\
\hline ZBIS $12-61-58$ & 2 \\
\hline hypogastric artery stent & \\
\hline Advanta V12 & 24 \\
\hline $7 \times 38$ & 1 \\
\hline $8 \times 38$ & 8 \\
\hline $8 \times 59$ & 2 \\
\hline $10 \times 38$ & 5 \\
\hline $10 \times 59$ & 3 \\
\hline $12 \times 41$ & 3 \\
\hline $12 \times 61$ & 1 \\
\hline $16 \times 61$ & 1 \\
\hline
\end{tabular}

contralateral side was achieved via brachial access in a second intervention four weeks later. Two other patients required coil embolization (Interlock -35 Fibered IDC Occlusion System, Boston Scientific, Marlborough, MA, USA) of the contralateral hypogastric artery because of a complex aneurysm extending into the internal pudendal artery, superior gluteal artery and obturator artery. In 16 patients with concomitant AAA the intervention was completed with a standard bifurcated aortic stent graft (Zenith, Cook Medical) that was introduced through a 18-F sheath (Medtronic, Minneapolis, MN) and placed at the infrarenal aorta directly distal to the origin of the renal arteries. Subsequently, a limb extension (Zenith, Cook Medical) with a proximal and distal diameter of $16 \mathrm{~mm}$ was used as a bridging stent between the bifurcated aortic main stent and the proximal part of the ISBD. No antibiotics were administered during the procedure.

\section{Results}

\section{$\nabla$}

\section{Procedural Results}

Procedures were performed with a mean operating time of 194 \pm 52 minutes (range 159 to 421 ) and a mean fluoroscopy time of $39 \pm 18$ minutes (range 12 to 70 ) with a dose-area product of $17345 \pm 8016 \mu \mathrm{Gy}^{*} \mathrm{~cm}^{2}$ (range 8419 to 39135 ). $164 \pm 44 \mathrm{ml}$ of iodinated non-ionic Iomeron 300 (range 105 to 232) was used. All stent grafts were deployed in intended positions with a patency of $100 \%$ ( $\bullet$ Fig. 1 ). In one case final angiogram showed a temporary endoleak type Ib that was no longer detectable in postoperative CTA. In one patient distal anchoring of the hypogastric artery stent graft led to iatrogenic perforation of the superior gluteal artery that was sealed with an additional stent graft (Advanta V12). In the same patient proximal extension with an aortic cuff was necessary to eliminate a perioperative endoleak type Ia. In one case positioning of the bridging stent was impossible despite the use of a stiff wire (Amplatz, Boston Scientific) caused by severe kinking of the iliac artery. After exchange to a super stiff wire (Lunderquist, Cook Medical) implantation was finally possible, however, cranial dislocation of the ISBD resulted in an endoleak type Ib with further pressurization of the iliac aneurysm sac causing a re-intervention. Conversion to open repair was not 

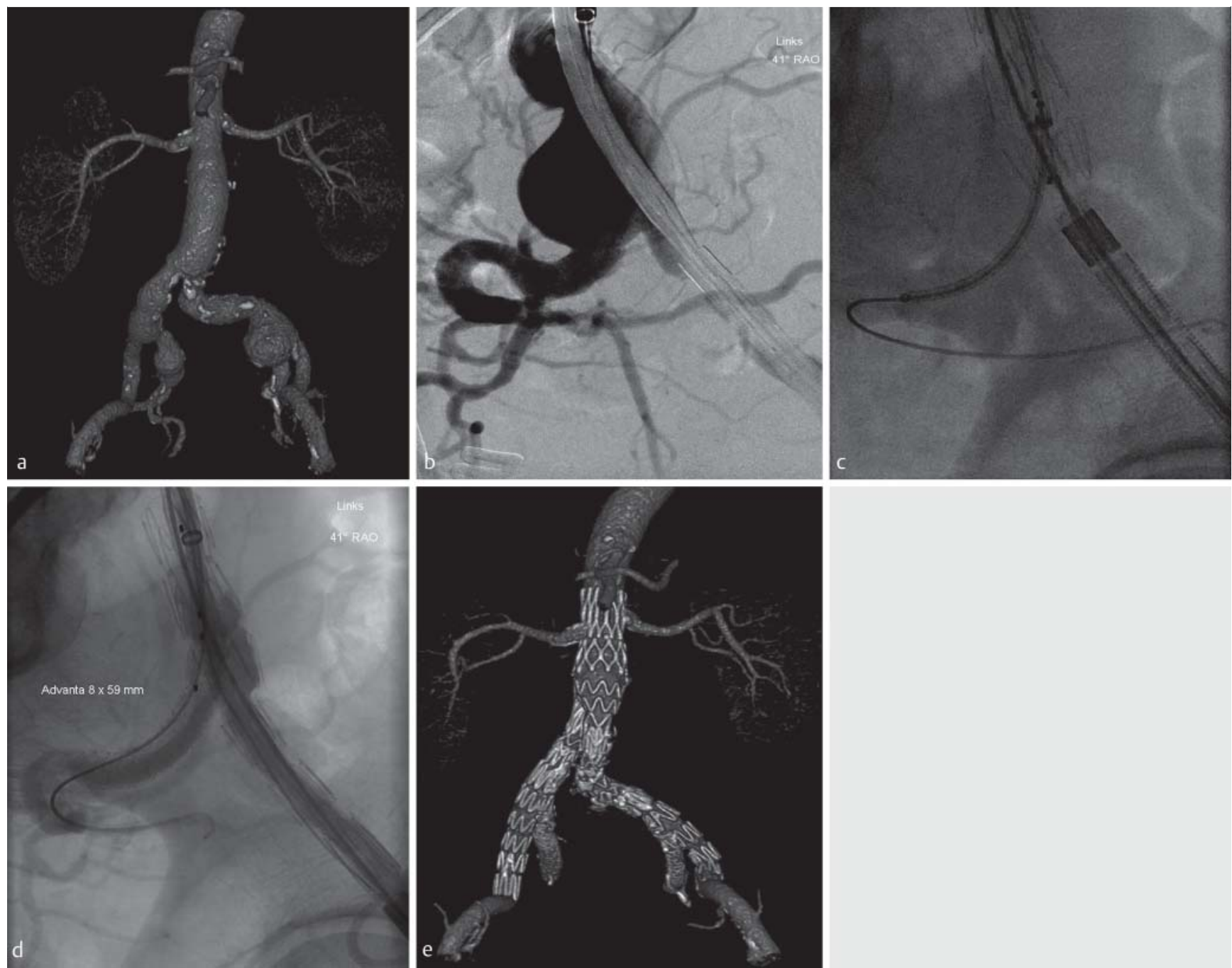

Fig. 1 a Pre-interventional CT imaging of a 73-year-old man with an AAA and concomitant bilateral CIA artery aneurysm and a right-sided hypogastric artery aneurysm. $\mathbf{b}$ Selective angiography shows left sided CIA artery aneurysm with incorporation of iliac bifurcation. c Partial deployment of ISBD with cannulated hypogastric artery and introduction of Advanta V12 stent. d Final angiography through the cross-over sheath confirms satisfactory position and patency of the hypogastric artery side branch. e Post-interventional result after bilateral implantation of iliac side branch devices and EVAR.

necessary. Summarized, rate of primary technical success was $94.4 \%$.

\section{Perioperative Clinical Results}

Mean hospitalization was $7 \pm 4.2$ days (range 3 to 14 ). All patients were observed postoperatively at an intermediate care unit for one night. Perioperative 30 days mortality was $0 \%$. Morbidity included wound healing disorder after surgical cut-down in one patient, which was treated with a vacuum assisted closure therapy. Another patient suffered from relevant postoperative inguinal hematoma requiring surgical intervention. No stent graft occlusion or other major complications occurred. Three patients (15\%) showed an endoleak type II from the inferior mesenteric artery, treated conservatively. In only one patient adjustment was necessary to successful eliminate an endoleak type Ib from the distal side branch in a re-intervention via a brachial access
Abb. 1 a Prä-interventionelle CT eines 73-jährigen Mannes mit einem abdominellen Aortenaneurysma und begleitenden bilateralen Aneurysmata der Arteriae iliacae communes und einem Aneurysma der Arteria iliaca interna rechts. b Selektive Angiografie des Aneurysmas der Arteria iliaca communis links mit Beteiligung der lliakalbifurkation. c Partielle Freisetzung der iliakalen Bifurkationsprothese mit kanülierter Arteria iliaca interna und eingebrachter Advanta-V12-Prothese. d Abschlussangiografie über die Cross-over-Schleuse mit Nachweis einer regelrechten Lage und Durchgängigkeit der Gefäßprothesen. e Post-interventionelles Ergebnis nach bilateraler Implantation iliakaler Bifurkationsprothesen und EVAR. where additionally an Advanta stent graft was implanted. At discharge, no patient suffered from buttock claudication or new-onset sexual dysfunction.

\section{Follow-up}

Mean follow-up period was $8.2 \pm 5.4$ months (range 1 to 20 ). Two patients were lost to follow-up after 6 months and 1 year. No patient died. No aneurysm rupture occured. One patient suffered from new onset of claudication ipsilateral to the ISBD after 3 months with pain-free walking capacity of 20 meters. Contrastenhanced CT scan demonstrated subtotal thrombotic occlusion of the bridging stent. Initial drug therapy with systemic heparinization did not achieve any relevant improvement. Accordingly, intra-arterial fibrinolytic therapy with 20 milligram alteplase was performed and a ballon-expandable stent graft (Genesis, Cordis) was deployed with restored patency ( $\bullet$ Fig. 2 ). During follow-up 

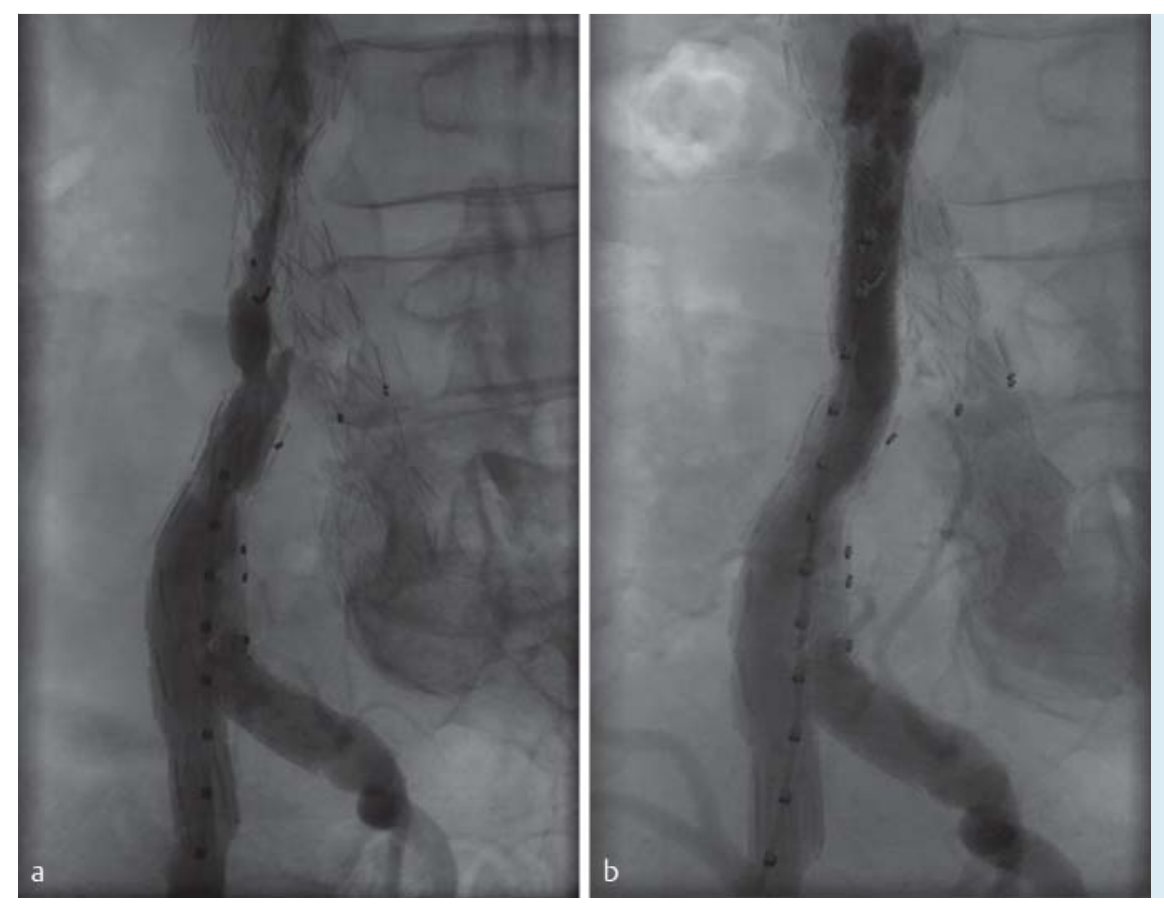

Fig. 2 a Angiography in a 85-year-old man with subtotal thrombotic occlusion of the bridging stent three months after implantation of the ISBD. $\mathbf{b}$ After intra-arterial fibrinolytic therapy combined with implantation of a ballon-expandable stentgraft patency is restored successfully.

Abb. 2 a 85-jähriger Mann mit subtotalem Verschluss des „bridging“-Stents drei Monate nach Implantation der iliakalen Bifurkationsprothese. $\mathbf{b}$ Erfolgreiche Wiedereröffnung des Lumens nach Kombination aus intra-arterieller Lyse und zusätzlich ballonexpandierbarer Stentimplantation.

patients with endoleak type II showed no relevant increase in aneurysm size.

\section{Discussion}

\section{$\nabla$}

EVAR is a safe and feasible minimal-invasive treatment option for AAA. However, a major drawback for the use of standard bifurcated stent grafts is the presence of iliac artery aneurysms. Especially, treatment of isolated iliac aneuryms is essential because of its high rate of rupture (5 to $70 \%$ over 5 years) and associated mortality (25 to $57 \%$ ) [19]. To overcome technical limitations of standard aortic stent grafts an option for concomitant iliac aneurysm exclusion is limb extension of the abdominal stent graft beyond the iliac aneurysm sac combined with occlusion of the hypogastric artery to prevent retrograde aneurysm perfusion. After embolization of the hypogastric artery, a time interval of several weeks is recommended to improve pelvic collateralization prior to final stent graft implantation. Unfortunately, ischemic complications such as buttock claudication or erectile dysfunction are often observed [20]. Our approach is to preserve perfusion to the hypogastric artery to avoid above mentioned drawbacks of embolization with the result that in our study no patient suffered from buttock claudication or new-onset sexual dysfunction after ISBD implantation. An ISBD is a standardized stent graft, which allows isolated iliac or aorto-iliac aneurysm exclusion while maintaining hypogastric artery perfusion. Implantation of ISBD may be performed in a one-stop-shop strategy combined with bifurcated aortic stent graft implantation in one session. Midterm results proved to be very benficial [14-16]. In our single center study we confirmed iliac side branch endografting as a technically feasible treatment option with a high patency rate in the absence of severe procedure-associated complications.

Particular anatomical conditions for successful ISBD implantation had to be considered with regard to (i) narrow lumen or stenosis of the CIA (e.g. thrombus, calcification), (ii) severe kinking of the EIA, (iii) stenotic ostium of the hypogastric artery, and (iv) wide an- gle $\left(>50^{\circ}\right)$ of the hypogastric artery origin [21]. These limiting factors are reported to strongly affect patency underlining the importance of careful patient selection. In our study one patient showed a cranial dislocation of the ISBD leading to an iliac endoleak type Ib. This complication was a result of severe kinking of the ipsilateral iliac axis and occurred while introducing a briding stent for completion of aorto-iliac aneurysm repair. A second intervention was necessary to extend the internal limb that was performed via a brachial access. Success rate in our study was $94.4 \%$, which is in accordance with results shown in previous studies ranging from $85-100 \%$ [14-16, 21 - 27]. Alternative techniques for iliac aneurysm exclusion like bell-bottom technique or embolization of the hypogastric artery show re-intervention rates up to $11 \%$ and $19 \%$, respectively [28]. We therefore consider ISBD as preferred approach in patients with adequate anatomy.

Appearance of endoleak may be an issue, which is already known from standard EVAR. Regular monitoring is recommended within the first year and annual examinations thereafter. Because of the modular design particular attention should be paid to the appearance of an endoleak type III, which is accompanied with persistent pressurization of the aneurysm. The overlapping zone of the bridging stent graft between the ISBD and bifurcated aortic main body is reported as one of the Achilles' heels $[15,16]$. Results reviewed in literature range from $0-10 \%$ in the perioperative period [14-17, 26]. In our study placement of the bridging stent graft was somewhat difficult in one patient characterized by severe iliac artery angulation, but no cases of endoleak type III were observed for this region. At the end of our relatively short follow-up three patients showed persistent endoleak type II without the need for re-intervention.

During the perioperative period no thrombosis occurred and branch patency was $100 \%$. However, in the follow-up period one patient presented subtotal thrombotic occlusion of the bridging stent. This is in accordance with the reported patency rates of $74-$ $90 \%[15,16,21-26]$. Recently, Maurel et al. reported three cases of branch thromboses after 30 days $(92 \%, n=39)$. In one case this was a result of ostial hypogastric artery stenosis [14]. This again empha- 
sizes the importance of careful patient selection regarding anatomical restriction for ISBD. Furthermore, it can be speculated that in many cases branch occlusions correlate with the operator's experience, since it is known that the hypogastric artery tends to dissect or even perforate in cases of rough cannulation or stenting [26]. Therefore, experienced catheterization skills are necessary. Ziegler et al. showed that there is no significant difference in first- or second-stent generations concerning patency rate [21].

Since iliac side branch endografts are available the use of practice raises, however, systematic reports on limitations of the device applicability are rare. In a study from 2010 it was pointed out that the morphological applicability of commercially available ISBD was low [29]. A recent study by Gray et al. showed that only a maximum of $58 \%$ of the patients in their cohort were within the manufacturer's IFU with the main limiting factor of an aneurysmal hypogastric artery that prevent adequate distal sealing [30]. In an adverse morphological situation, extending the landing zone more distally in the hypogastric artery is possible, but the risk of a worse result by sacrificing smaller branches with an increased risk of endoleak type II is given [30]. Furthermore, the risk of endoleak type Ib could be higher when choosing a shorter landing zone in the more distal branches of hypogastric artery. In our study all patients were within in the IFU including two cases presenting hypogastric artery aneurysm in the proximal main branch with a sufficient distal landing zone.

A major limitation of this study is the retrospective design with the attendant selection bias. The study cohort is small, however, this study is a single-center experience with isolated CIA aneurysms including those who presented with associated AAA. The small sample size precludes profound statistical analysis, therefore larger-scale studies are needed. Furthermore, the data subject to interobserver variability due to the participation of several operators. As the study included consecutive patients with suitable anatomic conditions, it reflects actual feasibility of this technique in the group of patients selected.

In conclusion, we consider iliac side branch devices to be feasible with distinguished short-term results in carefully selected patients. Larger series are needed to confirm efficacy as well as long-term durability.

\section{Clinical Relevance}

In patients with aortoiliac aneurysm iliac side branch devices avoid unilateral sacrificing of the hypogastric artery with the prevention of side effects such as buttock claudication and sexual dysfunction.

Careful patient selection is necessary due to limitations of graft applicability.

Endovascular repair via iliac side branch stent grafts is technical feasible with distinct short-term results.

\section{References}

1 Lederle FA, Freischlag JA, Kyriakides TC et al. Long-term comparison of endovascular and open repair of abdominal aortic aneurysm. The New England journal of medicine 2012; DOI: 10.1056/NEJMoa1207481

2 Becquemin JP, Pillet JC, Lescalie F et al. A randomized controlled trial of endovascular aneurysm repair versus open surgery for abdominal aortic aneurysms in low- to moderate-risk patients. Journal of vascular surgery 2011; DOI: 10.1016/j.jvs.2010.10.124

3 De Bruin JL, Baas AF, Buth J et al. Long-term outcome of open or endovascular repair of abdominal aortic aneurysm. The New England journal of medicine 2010; DOI: 10.1056/NEJMoa0909499
4 Greenhalgh RM, Brown LC. United Kingdom ETI. et al. Endovascular versus open repair of abdominal aortic aneurysm. The New England journal of medicine 2010; DOI: 10.1056/NEJMoa0909305

5 Brunkwall J, Hauksson $\mathrm{H}$, Bengtsson $\mathrm{H}$ et al. Solitary aneurysms of the iliac arterial system: an estimate of their frequency of occurrence. Journal of vascular surgery 1989; 10: $381-384$

6 Hobo R, Sybrandy JE, Harris PL et al. Endovascular repair of abdominal aortic aneurysms with concomitant common iliac artery aneurysm: outcome analysis of the EUROSTAR Experience. Journal of endovascular therapy: an official journal of the International Society of Endovascular Specialists 2008; DOI: 10.1583/07-2217.1

7 Luo H, Huang B, Yuan D et al. 8-Year Long-Term Outcome Comparison: Two Ways to Exclude the Internal Iliac Artery during Endovascular Aorta Repair (EVAR) Surgery. PloS one 2015; DOI: 10.1371/journal. pone.0130586

8 Lee WA, O'Dorisio J, Wolf YG et al. Outcome after unilateral hypogastric artery occlusion during endovascular aneurysm repair. Journal of vascular surgery 2001; DOI: 10.1067/mva.2001.114999

9 Mehta M, Veith FJ, Ohki T et al. Unilateral and bilateral hypogastric artery interruption during aortoiliac aneurysm repair in 154 patients: a relatively innocuous procedure. Journal of vascular surgery $2001 ; 33$ : S27-S32

10 Bergamini TM, Rachel ES, Kinney EV et al. External iliac artery-to-internal iliac artery endograft: a novel approach to preserve pelvic inflow in aortoiliac stent grafting. Journal of vascular surgery 2002; 35: 120 124

11 Parodi JC, Ferreira M. Relocation of the iliac artery bifurcation to facilitate endoluminal treatment of abdominal aortic aneurysms. Journal of endovascular surgery: the official journal of the International Society for Endovascular Surgery 1999; DOI: 10.1583/10746218(1999)006<0342:ROTIAB >2.0.CO;2

12 Torsello G, Schonefeld E, Osada $N$ et al. Endovascular treatment of common iliac artery aneurysms using the bell-bottom technique: longterm results. Journal of endovascular therapy: an official journal of the International Society of Endovascular Specialists 2010; DOI: 10.1583/ 10-3112.1

13 Paraskevas KI, Mollendorf C, Fernandes E et al. EVAR for aortoiliac aneurysms, including iliac branched grafts. The Journal of cardiovascular surgery 2012; 53: $67-72$

14 Maurel B, Bartoli MA, Jean-Baptiste E et al. Perioperative evaluation of iliac ZBIS branch devices: a French multicenter study. Annals of vascular surgery 2013; DOI: 10.1016/j.avsg.2011.02.052

15 Pua U, Tan K, Rubin BB et al. Iliac branch graft in the treatment of complex aortoiliac aneurysms: early results from a North American institution. Journal of vascular and interventional radiology: JVIR 2011; DOI: 10.1016/j.jvir.2011.01.429

16 Malina M, Dirven M, Sonesson B et al. Feasibility of a branched stentgraft in common iliac artery aneurysms. Journal of endovascular therapy: an official journal of the International Society of Endovascular Specialists 2006; DOI: 10.1583/05-1795R.1

17 Serracino-Inglott F, Bray AE, Myers $P$. Endovascular abdominal aortic aneurysm repair in patients with common iliac artery aneurysms-Initial experience with the Zenith bifurcated iliac side branch device. Journal of vascular surgery 2007; DOI: 10.1016/j.jvs.2007.03.040

18 Wong S, Greenberg RK, Brown CR et al. Endovascular repair of aortoiliac aneurysmal disease with the helical iliac bifurcation device and the bifurcated-bifurcated iliac bifurcation device. Journal of vascular surgery 2013; DOI: $10.1016 /$ j.jvs.2013.02.033

19 Melas N, Saratzis A, Dixon $\mathrm{H}$ et al. Isolated common iliac artery aneurysms: a revised classification to assist endovascular repair. Journal of endovascular therapy: an official journal of the International Society of Endovascular Specialists 2011; DOI: 10.1583/11-3519.1

20 Lee CW, Kaufman JA, Fan CM et al. Clinical outcome of internal iliac artery occlusions during endovascular treatment of aortoiliac aneurysmal diseases. Journal of vascular and interventional radiology: JVIR 2000; 11: $567-571$

21 Ziegler P, Avgerinos ED, Umscheid T et al. Branched iliac bifurcation: 6 years experience with endovascular preservation of internal iliac artery flow. Journal of vascular surgery 2007; DOI: 10.1016/ j.jvs.2007.04.015

22 Karthikesalingam A, Parmar J, Cousins C et al. Midterm results from internal iliac artery branched endovascular stent grafts. Vascular and endovascular surgery 2010; DOI: 10.1177/1538574409352692 
23 Tielliu IF, Bos WT, Zeebregts CJ et al. The role of branched endografts in preserving internal iliac arteries. The Journal of cardiovascular surgery 2009; 50: $213-218$

24 Lee WA. Branched endograft for aortoiliac artery aneurysms. Vascular 2009; 17/3: S111-S118

25 Ghosh J, Murray D, Paravastu S et al. Contemporary management of aorto-iliac aneurysms in the endovascular era. European journal of vascular and endovascular surgery: the official journal of the European Society for Vascular Surgery 2009; DOI: 10.1016/j.ejvs.2008.11.001

26 Dias NV, Resch TA, Sonesson B et al. EVAR of aortoiliac aneurysms with branched stent-grafts. European journal of vascular and endovascular surgery: the official journal of the European Society for Vascular Surgery 2008; DOI: 10.1016/j.ejvs.2007.10.022

27 Bisdas T, Weiss K, Donas KP et al. Use of iliac branch devices for endovascular repair of aneurysmal distal seal zones after EVAR. Journal of endovascular therapy: an official journal of the International Society of Endovascular Specialists 2014; DOI: 10.1583/14-4712R.1
28 Naughton PA, Park MS, Kheirelseid EA et al. A comparative study of the bell-bottom technique vs hypogastric exclusion for the treatment of aneurysmal extension to the iliac bifurcation. Journal of vascular surgery 2012; DOI: 10.1016/j.jvs.2011.10.121

29 Karthikesalingam A, Hinchliffe RJ, Malkawi AH et al. Morphological suitability of patients with aortoiliac aneurysms for endovascular preservation of the internal iliac artery using commercially available iliac branch graft devices. Journal of endovascular therapy: an official journal of the International Society of Endovascular Specialists 2010; DOI: $10.1583 / 09-2942.1$

30 Gray D, Shahverdyan R, Jakobs $C$ et al. Endovascular aneurysm repair of aortoiliac aneurysms with an iliac side-branched stent graft: studying the morphological applicability of the Cook device. European journal of vascular and endovascular surgery: the official journal of the European Society for Vascular Surgery 2015; DOI: 10.1016/j.ejvs.2014.12.021 